\title{
Os Planos de Turismo da Espanha como ferramenta para os estudos da sazonalidade
}

\author{
Fabiana Calçada de Lamare Leite* \\ Instituto Federal de Santa Catarina (Brasil)
}

\author{
Thays Domareski Ruiz**
}

Universidade do Vale do Itajaí (Brasil)

\begin{abstract}
Resumo: A sazonalidade é uma característica inerente ao turismo. O objetivo do estudo foi descrever e analisar os planos de turismo espanhóis como ferramenta para os estudos da sazonalidade. Para isso, adotou-se como referência o modelo de planejamento turístico espanhol, com os Planos de Excelência Turística e, posteriormente com o Plano Nacional Horizonte 2020. Foram desenvolvidos estudos de caráter descritivo e analítico com fundamentos teórico-conceitual, de abordagem qualitativa. Como técnicas, a pesquisa utilizou-se de pesquisa bibliográfica e de pesquisa documental, onde o estudo se desenvolveu por meio de uma pesquisa sobre os temas: turismo, planejamento e sazonalidade, além dos planos de turismo espanhóis. Destacou-se que a sazonalidade é uma temática importante a ser trabalhada no planejamento turístico dos destinos, onde a falta de instrumentos de planejamento representa a possibilidade de uma ocorrência da atividade turística desordenada e com pouco entendimento entre as dinâmicas turísticas tendo como consequência a desregulamentação da atividade.
\end{abstract}

Palavras-chave: Turismo; Sazonalidade; Planos de Turismo; Planejamento Turístico; Espanha.

\section{Spanish Tourism Plans as a tool for seasonality studies}

Abstract: Seasonality is an inherent feature of tourism. The objective was to describe and analyze Spanish tourism plans as a tool for studies of seasonality. To this end, the Spanish tourism planning model was adopted as a reference, with the Tourism Excellence Plans and later the National Horizon 2020 Plan. Descriptive and analytical studies were developed with a theoretical-conceptual basis, in a qualitative approach. As techniques, the research used bibliographic research and documentary research, where the study was developed through research into the areas of tourism, planning and seasonality beyond the Plan. It was pointed out that seasonality is an important theme to be worked on in tourist planning of destinations, where the lack of planning instruments creates the possibility of disordered tourist activity and tourism dynamics producing deregulation of the activity.

Keywords: Tourism; Seasonality; Tourism Plans; Tourism Planning; Spain.

\section{Introdução}

Nos últimos anos, o turismo se destacou como um dos setores de mais rápido crescimento e mais rentáveis da economia de um país, agregando valor ao $\mathrm{PIB}^{1}$ e proporcionando maior qualidade de vida para a população (Sánchez \& López, 2014) e contribuindo para o desenvolvimento econômico local e nacional (Trajkov, Biljan, Andreeski, 2016). Reconhecida como um fator de desenvolvimento econômico, a atividade turística é um elemento estruturador do território que pode gerar impactos positivos e negativos.

* Doutorado em Geografia pela Universidade Federal do Paraná; Professor no Instituto Federal de Santa Catarina, Brasil; E-mail: fabianac@ifsc.edu.br

** Doutorado em Geografia pela Universidade Federal do Paraná; Professora da Universidade Federal do Paraná, Brasil;E-mail: thaysdomareski@gmail.com 
Uma das mais importantes e relevantes definições de sazonalidade foi elaborada por Richard Butler, onde, a sazonalidade é considerada um desequilíbrio temporal do turismo, que pode ser expresso e ou medido em número de visitantes, despesas de visitantes, tráfego em rodovias e em outras formas de transporte, emprego e entradas em atrativos turísticos (Butler, 2001).

Uma série de revisões teóricas importantes sobre a temática da sazonalidade já foram realizadas (Baum \& Lundtorp, 2001; Butler, 2001; Koenig-Lewis \& Bischoff, 2003; Koenig-Lewis \& Bischoff, 2005, Jang, 2004), e também pesquisas quantitativas (Coshall et al., 2013; Trajkov; Biljan \& Andreeski, 2016).

Entender o conceito de sazonalidade não se restringe aos limites do conceito apresentado pelo setor turístico. A sazonalidade é um conceito transversal que atende a diversos setores da economia. Por isso, torna-se importante compreender esse conceito em um âmbito mais abrangente para, posteriormente, focar no seu entendimento para o turismo. No turismo, a sazonalidade é peculiar e apresenta-se como um desafio aos planejadores dos destinos turísticos na elaboração de políticas para o seu desenvolvimento.

A sazonalidade é inerente ao turismo e se apresenta como um desafio ao planejamento dos destinos turísticos no qual o próprio setor estuda e implementa ações que visam reduzir ou amenizar seus efeitos (Allcock, 1989; Baron, 1975; Baum \& Lundtorp, 2001; Butler, 2001; Trajkov, Biljan, Andreeski, 2016). Para tentar controlar os impactos negativos, também oriundos da sazonalidade, como a inflação, a especulação imobiliária, a dependência excessiva do turismo, a degradação ambiental, dentre outros aspectos, se faz necessária a incorporação de processos de planejamento da atividade por meio de planos e medidas legislativas (Secall, 2012).

O presente artigo aborda a importância e o papel dos planos turísticos para o planejamento e organização do território de um destino turístico. Por ser a atividade turística um dos principais segmentos econômicos da Espanha, o governo tem apoiado importantes iniciativas para impulsionar o setor. Diante do exposto, o objetivo foi analisar os planos de turismo espanhóis como ferramenta para os estudos da sazonalidade. $\mathrm{O}$ foco é a abordagem que possibilite ações para minimizar a sazonalidade. Para isso, adotou-se como referência o modelo de planejamento turístico espanhol, com os Planos de Excelência Turística e o Plano Nacional Horizonte 2020.

Pretende-se refletir que, por meio de um plano, com um planejamento adequado, as dificuldades podem ser superadas convertendo a baixa temporada do turismo em uma oportunidade de equilíbrio da demanda e, como consequência gerar maior equilíbrio econômico oriundo da atividade turística, beneficiando o município como um todo. Dessa maneira, por reunir atributos como infraestrutura e oportunidades inerentes de localização e de escala para experiências diversas, a cidade torna-se atrativa e se insere no turismo em diversas perspectivas de segmentação (KARSKI, 1990; LAW, 2006).

Poucos são os destinos que não apresentam sazonalidade, por isso, os agentes públicos e privados deveriam se preocupar no intuito de definir estratégias que possibilitem minimizar os seus efeitos negativos (Baron, 1975; Butler, 2001).

As transformações registradas no mercado turístico somadas à evolução e ao ciclo de vida dos destinos turísticos e a consequente necessidade de adaptação dos espaços receptores às novas dinâmicas globais, justificam a necessidade de debater maneiras de trabalho para a renovação dos destinos turísticos de litoral que se encontram consolidados (Rebollo \& Castiñera, 2010).

Sobre isso, Secall (2012), refere-se ao modelo turístico espanhol do final da década de 1980 que se caracterizava pelo crescimento desregulado e pela concentração espacial tanto pelo número de visitantes quanto pela localização dos meios de hospedagem, afirmando que o crescimento acelerado, muito associado aos interesses econômicos, se realizou de maneira improvisada, desordenada, sem quase nenhum tipo de planejamento que contempla as necessidades de infraestruturas e serviços.

No caso espanhol, mesmo com um crescimento do fluxo turístico durante o restante do ano, a concentração do fluxo turístico para a Espanha continua no verão. Isso se reflete na elevada sazonalidade que gera a saturação dos destinos na alta temporada afetando os níveis de satisfação da demanda (Plan de Turismo Español Horizonte 2020, 2007).

Os Planos de Excelência Turística (PET) foram um instrumento desenvolvido desde o início da década de 1990 pelo Estado Espanhol em parceria com a administração regional e local, fundamentado na importância de minimizar a sazonalidade em resposta ao declive identificado nos destinos turísticos maduros / consolidados, especialmente de sol e praia. Estes documentos constituem-se de propósitos, dentre os quais se destaca a intenção de incrementar a economia aumentando a rentabilidade dos agentes turísticos por meio da redução da sazonalidade (Plan de Turismo Español Horizonte 2020, 2007).

Além desta introdução, este artigo apresenta mais 4 seções. Na seção 2 são apresentados os procedimentos metodológicos. Na seção 3, apresenta-se a revisão de literatura sobre a sazonalidade e a importância do planejamento. Na seção 4 são apresentados os resultados da pesquisa, e, finalmente, na seção 5 são apresentadas as considerações finais do artigo. 


\section{Procedimentos Metodológicos}

Foram desenvolvidos estudos de caráter descritivo e analítico com fundamentos teórico-conceitual, de abordagem qualitativa. A pesquisa descritiva é utilizada quando o pesquisador tem interesse em compreender diversos fatores e elementos que influenciam direta ou indiretamente o tema estudado (Richardson, 1999). Assim, os estudos descritivos transmitem uma constatação, enriquecida muitas vezes com cruzamento de informações (Munhoz, 1989).

Como técnicas, a pesquisa utilizou-se de pesquisa bibliográfica e de pesquisa documental, onde o estudo se desenvolveu por meio de uma pesquisa sobre os temas: turismo, planejamento e sazonalidade, além dos planos de turismo espanhol referenciais. O período de análise dos artigos buscou analisar o panorama dos estudos sobre a sazonalidade.

A pesquisa documental pode representar um caráter inovador vindo a contribuir significativamente com alguns estudos (Godoy, 1995). No caso, os principais documentos analisados são os Planos de Excelência Turística (PET) o Plano Nacional Espanhol Horizonte 2020.

A Espanha foi escolhida pela relevância da atividade turística para a sua economia, e será apresentada na sequência. Assim, iniciou-se a pesquisa investigando a existência de políticas de planejamento turístico, em especial, que abordasse a temática da sazonalidade. Inicialmente foram estudados os Planos de Excelência Turística por terem constituído um dos mais importantes instrumentos da política turística espanhola, visto que abordou possibilidades para melhorar a qualidade dos destinos turísticos fundamentado na importância de minimizar a sazonalidade especialmente em destinos de Sol e Praia (Secall, 2012). Posteriormente, a partir do conhecimento obtido por meio Planos de Excelência Turística na Espanha, adotou-se como referência teórica documental o Plano de Turismo Espanhol Horizonte 2020 visto como uma melhoria para a concepção de novas iniciativas de políticas para o turismo, abordando estratégias para a minimização da sazonalidade turística de início por meio dos planos de dinamização do produto turístico (2006-2008) e, posteriormente com os planos de competitividade turística.

Para tanto, foram utilizados: periódicos, livros, artigos referentes à temática do estudo. Uma das vantagens da fonte bibliográfica para a investigação é permitir que o investigador tenha como consulta uma gama de fenômenos muito mais amplos do que poderia buscar diretamente (Gil, 1999).

A abordagem metodológica que caracteriza a presente pesquisa é qualitativa, que visa compreender ou interpretar processos de forma complexa e contextualizada e se caracteriza como um plano aberto e flexível (Dencker, 1998). Na pesquisa qualitativa, o pesquisador participa e interpreta os fatos, usando análises consistentes e coerentes como argumentação para fundamentar suas ideias (Michel, 2005).

\section{Quadro 01: Procedimento Metodológico;}

\begin{tabular}{|l|l|}
\hline Base de Dados & EBSCO; Science Direct; Scopus; \\
\hline Bibliografia & $\begin{array}{l}\text { Dados secundários; } \\
\text { Trabalhos publicados de 1975 à 2016; }\end{array}$ \\
\hline Documentos & $\begin{array}{l}\text { Planos de Excelência Turística (PET); } \\
\text { Plano Nacional Espanhol Horizonte 2020; }\end{array}$ \\
\hline Estratégia de Pesquisa & $\begin{array}{l}\text { Uso das palavras: sazonalidade; planejamento, plano de turismo; } \\
\text { política de turismo, (português/espanhol); }\end{array}$ \\
\hline Critério & No título, abstract ou palavras-chave; \\
\hline Abordagem & Qualitativa; \\
\hline Análise & Descritiva e analítica; \\
\hline
\end{tabular}

Fonte: elaboração própria, 2017.

\subsection{Espanha: objeto de estudo}

A Espanha está localizada no continente europeu, onde a maior parte de seu território localiza-se na Península Ibérica e o restante, em torno de $12.500 \mathrm{~km}^{2}$, são as Ilhas Baleares e o Arquipélago das Canárias, além de $32 \mathrm{~km}^{2}$ que correspondem às cidades de Ceuta e Melila, situadas na costa Africana, totalizando uma população de aproximadamente 47 milhões de habitantes (Turespaña, 2016). 
Além disso, o Instituto de Turismo da Espanha destaca que a situação da Península Ibérica no extremo sul ocidental da Europa, distante apenas $14 \mathrm{~km}$ do continente africano, posiciona estrategicamente a Espanha: projeção mediterrânea por um lado e, por outro, como posição central para a África e para a América (Turespaña, 2016).

O desenvolvimento do turismo na Espanha tem precedentes nas regiões litorâneas do Norte (San Sebastian e Santander), mas se configura como uma atividade massiva a partir dos anos de 1970 na costa mediterrânea e nas Ilhas Canárias (Soares, 2012). A partir da década de 1980, a Espanha desenvolveu o turismo de maneira relevante e, de acordo com o Banco Mundial (2012), é responsável por $5.5 \%$ das chegadas de turistas internacionais do mundo, o que representa o país como consolidado para o produto turístico mundial (Soares, 2012).

Em termos de infraestrutura turística, a Espanha possui qualidade internacional e apresenta como os principais pontos: recursos culturais, equipamentos turísticos, infraestrutura de transporte aéreo e a prioridade com a indústria turística (Soares, 2012).

De acordo com o World Travel and Tourism Council, a contribuição direta do turismo para o PIB em 2016 foi de 57,1 bilhões de euros (5,1\% do PIB). Estima-se que no final de 2017 ocorra um aumento de 3,5\% atingindo a marca de 59,1 bilhões de euros. Isso reflete principalmente a atividade econômica gerada por hotéis, agências de viagens, entrada de atrativos turísticos como museus, teatros, parques temáticos entre outros, companhias aéreas e outros meios de transporte de passageiros. Em uma perspectiva positiva, espera-se que a contribuição direta do turismo para o PIB aumente de $2,0 \%$ por ano chegando a 72,1 bilhões de euros (5,5\% do PIB) até 2027 (WTTC, 2017). A Espanha é um dos principais destinos turísticos internacionais e o turismo representa uma importante fonte de renda e de geração de empregos para o país (Soares, 2012). O ensejo de adotar os planos espanhóis como referência, soma-se ao destaque de ser a Espanha o terceiro destino turístico mais visitado do mundo, com cerca de 65 milhões de chegadas e o primeiro lugar em competitividade turística mundial de 2015 (WEF, 2015).

\section{Fundamentação Teórica}

Nesta sessão busca-se apresentar as temáticas que foram necessárias para o desenvolvimento da pesquisa. Para uma melhor compreensão da ocorrência da atividade turística em benefício da localidade e da sua comunidade é importante pensar a sazonalidade e planejar a distribuição da atividade turística, com equilíbrio entre a oferta e a demanda. Nesse sentido, os autores destacam que, mesmo a sazonalidade sendo uma das características mais destacadas do turismo, é também uma das menos examinadas (Allcock, 1989; Butler, 2001; Jang, 2004).

Nas palavras de Scheuer (2011:291), "o turismo planejado e ordenado de forma adequada pode auxiliar as comunidades a minimizar os impactos negativos advindos do turismo sazonal".

Aproximando a compreensão do conceito de sazonalidade para a atividade turística, um dos primeiros pesquisadores a iniciar essa discussão foi BarOn (1975) ao afirmar a sazonalidade como uma utilização incompleta e desequilibrada dos meios econômicos, semelhante ao desequilíbrio do ciclo de negócios. BarOn (1975) definiu, ainda, a sazonalidade como os efeitos que ocorrem a cada ano decorrentes do clima, restrições de datas festivas, atrações especiais ou estilo de vida pessoal.

Baseado nos estudos de BarOn (1975), Butler (1994) é um dos autores mais referenciados no turismo para os estudos sobre sazonalidade e apresenta o conceito com a definição de um desequilíbrio temporal no fenômeno do turismo, que pode ser expresso em dimensões como o número de visitantes, as despesas geradas por eles, o tráfego nas rodovias e demais meios de transporte e número de empregos gerados em atrativos/serviços turísticos.

Ruschmann (2004) é direta ao afirmar que a sazonalidade é decorrente da concentração de atividades turísticas no espaço e no tempo. De uma maneira geral, o entendimento sobre sazonalidade passa por ideias como concentração dos fluxos turísticos em períodos determinados do ano, concentração de atividades, saturação de uso dos recursos, entre outros aspectos, causando picos na prestação de serviços e na presença de turistas.

Além disso, há muitos fatores que têm um impacto na sazonalidade do turismo. Eles podem ser agrupados em fatores naturais e sociais (Lee et al., 2008; Secareanu \& Firoiu, 2011; Kožić, 2013). Os fatores naturais referem-se às alterações estações e características geográficas do destino turístico. Os fatores sociais são as leis e regras escritas, costumes e tradições em determinado lugar e, portanto, influenciam na dinâmica das atividades turísticas. A sazonalidade apresenta-se como um dos principais desequilíbrios dos destinos turísticos e as consequências são evidenciadas por motivos referentes ao 
calendário de trabalho e ao calendário escolar, por questões ambientais, climáticas ou econômicas (Trajkov; Biljan \& Andreeski, 2016).

A sazonalidade implica, de fato, em um dos parâmetros essenciais para promover um desenvolvimento sustentável da atividade turística no território e é objeto de destaque no planejamento estratégico turístico territorial (Duro \& Farré, 2015). Com o foco na temática da sazonalidade, foi possível identificar a relevância do planejamento turístico para um destino, considerando a suas especificidades de oferta e demanda para ações direcionadas e fundamentadas.

Se a redução da sazonalidade em uma determinada localidade for alcançada pelo incremento da procura em baixa temporada pode-se esperar uma maior eficiência da atividade turística, assim como um crescimento global real da procura e das receitas. (Almeida \& Kastenholz, 2008). O estudo da sazonalidade se apresenta de maneira que venha a atenuar esse fenômeno e, consequentemente, entender e gerir as consequências geradas por ele.

Além disso, por meio da implantação de ações e medidas de diferenciação ou renovação com a intenção de intervir nos períodos sazonais, pode ser possível manter uma localidade atrativa. Neste sentido, o turismo assume papel de destaque como estratégia de desenvolvimento local.

Assim, com a atividade turística mais equilibrada e distribuída ao longo do ano, torna-se possível imaginar um desenvolvimento turístico sustentado, pois estabiliza as expectativas, a demanda local de mão de obra, a produção e oferta de serviços, minimizando os efeitos da sazonalidade e contribuindo para o melhor desenvolvimento do destino turístico.

Sobre as consequências da sazonalidade, em uma caracterização clássica, elas podem ser identificadas e agrupadas em três categorias: Econômica, Social e Ambiental (Correa, 1994; Cannas, 2012), conforme é possível observar no quadro 02.

\section{Quadro 02: Sazonalidade: Consequências / Impactos;}

\begin{tabular}{|c|c|l|}
\hline Consequências & Área & \multicolumn{1}{c|}{ Impactos } \\
\hline \multirow{2}{*}{ Economia } & Economia & $\begin{array}{l}\text { Flutuação da receita, inflação local, especulação } \\
\text { imobiliária, geração (e retração) de empregos, } \\
\text { concentração de investimentos e perda de investimentos } \\
\text { alternativos. }\end{array}$ \\
\cline { 2 - 3 } & $\begin{array}{c}\text { Comércio e } \\
\text { Serviços }\end{array}$ & $\begin{array}{l}\text { Aumento da oferta local, provimento de fluxo direcionado, } \\
\text { fechamento de estabelecimentos, falta de serviços } \\
\text { regulares. }\end{array}$ \\
\hline \multirow{2}{*}{ Social } & $\begin{array}{c}\text { Sociedade e } \\
\text { Cultura }\end{array}$ & $\begin{array}{l}\text { Costumes e tradições postos em cheque, emigração da } \\
\text { comunidade local, falta de regularidade na oferta de mão- } \\
\text {-de-obra especializada, custos sociais (drogas, violência, } \\
\text { etc.). }\end{array}$ \\
\cline { 2 - 3 } & $\begin{array}{c}\text { Política e } \\
\text { Administração }\end{array}$ & $\begin{array}{l}\text { Necessidade de um desenvolvimento local integrado, } \\
\text { segregação socioespacial. }\end{array}$ \\
\hline Ambiental & Meio Ambiente & $\begin{array}{l}\text { Novas instalações e infraestrutura, degradação ambiental, } \\
\text { poluição, produção excessiva e sazonal de resíduos sólidos. }\end{array}$ \\
\hline
\end{tabular}

Fonte: Adaptado de Correa, 1994; Cannas, 2012.

A sazonalidade é um problema do turismo que, a longo prazo, pode afetar muitas atividades, especialmente nos destinos turísticos litorâneos (Cisneros-Martínez \& Fernández-Morales, 2013). As consequências econômicas referem-se, essencialmente, aos períodos de baixa temporada, pela perda de lucro devido ao ineficiente uso dos recursos turísticos (Cannas, 2012; Martins, 2010; Baum \& Lundtorp, 2001). Pela instabilidade econômica, torna-se difícil atrair investimentos privados permanentes, sendo necessário o investimento público como alicerce econômico. Em decorrência desse processo, a sazonalidade em um destino caracteriza períodos com alta especulação imobiliária, "inflacionamento temporal" devido ao período de grande procura e falta de regularidade da oferta de serviços.

Os impactos sociais e socioculturais relacionam-se não somente a comunidade local, mas também, aos turistas. No período de alta concentração de turistas os impactos podem estar relacionados ao "convívio" 
social no que se refere a congestionamentos e filas para os serviços, saturação da infraestrutura local o que pode levar a uma diminuição na qualidade de vida dos residentes. A oscilação na oferta e procura de serviços pode gerar um fluxo emigratório para localidades onde a oferta e permanência do emprego seja mais estável, isso pode representar falta de mão-de-obra especializada. A criação de emprego pelo turismo é positiva, no entanto, pode trazer efeitos desestabilizadores para a economia local, pois desloca trabalhadores dos empregos permanentes para ocupações sazonais.

Os impactos categorizados como ambientais estão relacionados principalmente às consequências dos excessos no período de alta visitação, tais como: acumulação de lixo e demais resíduos, poluição, degradação ambiental, ocupações irregulares e que afetam a capacidade de carga do destino.

Planejar implica em identificar variáveis para adotar um curso de ação, com análises que permitam alcançar uma situação pré-determinada com o objetivo de organizar e melhorar a vida dos cidadãos de uma localidade (Molina, 1997). O planejamento para ser executado, deve considerar não apenas o prático e racional, neste processo, devem ser considerados os atores envolvidos para que a ação de planejamento seja harmônica com o ambiente e com as pessoas que com ele convivem (Leite \& Henz, 2016).

O planejamento urbano deve ocorrer de maneira articulada ao planejamento do turismo para a ocorrência de um turismo atrativo e competitivo para a localidade. As duas práticas de planejamento ocorrendo de maneira articulada podem beneficiar o desenvolvimento local, influenciando na qualidade de vida da população local e, consequentemente, beneficiando a atividade turística (Costa, 2001).

Costa (2001) aborda o tema do planejamento do turismo em paralelo ao planejamento da cidade, entendendo que a atividade de planejar o espaço para o turismo está relacionada ao planejamento da cidade no que se refere às atuações e configurações urbanas, assim como, ao modo de vida e de pensar que se reflete nas novas formas de atuar sobre o espaço e seus agentes condicionantes. Dessa forma, a proximidade entre o planejamento da cidade e o planejamento do turismo é a razão para o planejamento do turismo esteja emergindo como uma especialização do planejamento urbano da cidade em função de necessidades e desejos dos residentes, forças do mercado e a posição do local no mercado mundial, como destino turístico (Costa, 2001).

O planejamento turístico pode ser entendido como uma função da política turística, a partir da qual, se definem objetivos, estratégias e atuações, a serem considerados em determinado território (Ivars, 2003). O planejamento também é uma ação tomada em consequência de um diagnóstico, da análise da situação atual de um destino turístico que deve estabelecer objetivos, metas e estratégias futuras (Hall, 2001).

Como exemplo, a importância de uma política de turismo, Ivars (2003) destaca que o desenvolvimento da política turística constitui um elemento essencial, mesmo não sendo o único, para identificar a origem e as características dos principais enfoques do planejamento turístico.

As medidas de planejamento e gestão para atenuar a sazonalidade de um destino não devem ser estudadas apenas no próprio destino. Deve-se levar em conta todo o movimento que é feito na busca por esse destino e assim desenvolver planos de ação, em conjunto com o perfil de demanda, que atendam às suas expectativas.

A transversalidade da atividade turística comporta distintos processos de planejamento que, apesar de não estar destinado especificamente ao setor turístico, apresentam certa influência sobre a atividade. Por isso, para controlar as instabilidades econômicas, a degradação ambiental e as desigualdades sociais, se faz necessária a incorporação de processos de planejamento turístico por meio de planos e medidas legais apoiadas pela administração pública, como o exemplo dos Planos de Excelência Turística (Secall, 2012).

Um exemplo da importância da temática da sazonalidade turística inserida em questões pensadas para o planejamento de um destino turístico encontra-se no Plano de Turismo Espanhol Horizonte 2020. Reconhecendo a importância do equilíbrio da demanda anual para um destino turístico, o documento constitui-se de propósitos dentre os quais se destaca a intenção de incrementar a economia aumentando a rentabilidade dos agentes turísticos por meio da redução da sazonalidade.

\section{Análise dos Dados e Discussão}

O turismo é uma atividade que necessita criar imagens e representações. Assim, os destinos turísticos devem ser recriados constantemente para se diferenciarem e despertar o interesse de potenciais visitantes (Urry,1995). Uma das maneiras de recriar e diferenciar destinos turísticos é implantando instrumentos de organização e política turística, como o caso dos planos estudados no presente estudo.

A busca pela diferenciação como maneira de reinvenção e novo posicionamento de um destino turístico possibilita a diversificação da oferta combinando segmentos turísticos distintos. Tal ação pode vir a 
melhorar a distribuição da oferta, minimizando os efeitos sazonais e melhor aproveitando a oferta e os recursos turísticos.

Os Planos de Excelência Turística (PET) foram um instrumento da política turística espanhola desenvolvido desde o início da década de 1990 a partir do Marco da Competitividade do Turismo na Espanha por parte do Estado Espanhol em parceria com a administração regional e local, fundamentado na importância de minimizar a sazonalidade em resposta ao declive detectado nos destinos turísticos maduros / consolidados, especialmente de Sol e Praia.

Segundo Bosque (2004), inicialmente, os PET se destinaram a recuperação dos destinos turísticos maduros / consolidados, cujo desenvolvimento turístico ocorreu de forma desordenada. Como exemplo, as ações propostas objetivavam combater, dentre outros, os problemas de saturação que geravam a queda na satisfação dos visitantes e a degradação dos espaços urbanos e naturais.

No contexto de reorientação do modelo turístico, os Planos de Excelência Turística constituíram uma das mais importantes iniciativas da política turística espanhola, visto que levantou diversas possibilidades para melhorar a qualidade dos destinos turísticos (Secall, 2012).

Roblez e López (2009) destacam que esses planos constituíram um programa de apoio à excelência turística nos destinos mais desenvolvidos do litoral espanhol e posteriormente sua dinamização com o objetivo de incorporar à atividade turística os destinos culturais, rurais ou de litoral que disponibilizavam de recursos potenciais de atração e de organização como um destino turístico.

Segundo Secall (2012) os planos têm como objetivo comum aumentar a qualidade dos serviços turísticos do destino, melhorar o seu meio urbano e natural, melhorar e ampliar a oferta de serviços complementares, valorizar os recursos turísticos e criar novos produtos, além de sensibilizar a população e os agentes locais.

Ivars (2003) aponta três razões para considerar como interessantes e importantes os planos de excelência turística: os planos fomentam a aplicação de instrumentos de planejamento que orientam os processos de reestruturação dos destinos maduros / consolidados e o desenvolvimento de novas áreas turísticas; os planos reforçam o reconhecimento da escala local como âmbito preferente de ações público-privadas para a consolidação de um modelo turístico competitivo e sustentável e por último, os planos incentivam o princípio de corresponsabilidade e de intervenção dos diferentes níveis administrativos.

Além disso, Bosque (2004) e Secall (2012) afirmam que os planos de excelência turística tem sido o reflexo de uma nova cultura turística espanhola, baseada no tratamento integral do destino, na liderança da administração e gestão local a partir da colaboração e cooperação administrativa na gestão e financiamento e inclui a participação de diversos agentes econômicos e sociais do destino. Isso justifica que uma das condições do plano seja introduzir ações que objetivem melhorar a totalidade do destino (Bosque, 2004), buscando de fato um planejamento integrado.

\section{Figura 02: Princípios básicos de um Plano de Excelência Turística}

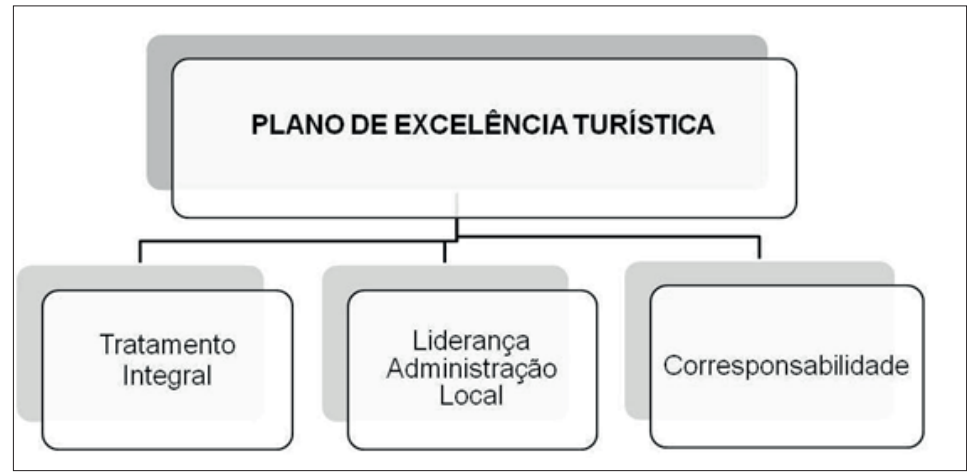

Fonte: Secall (2012).

O destino turístico trabalhado de maneira global organiza suas ações de forma que incidam em todos os aspectos e envolvam todos os agentes que intervém na atividade turística, direta ou indiretamente. Nos PET o papel da administração local na gestão e planejamento das áreas turísticas é incentivado e a 
liderança local é fundamentada no princípio da cooperação financeira ou de consultoria com as demais esferas governamentais e privadas.

Como prioridade para os PET, o Departamento Geral de Turismo de Madrid (1998) resume como importantes ações que são perceptíveis pelos turistas e que devem ser tomadas:

- Melhoria nas praias: limpeza e implantação de serviços de vigilância, sanitários, cestos de lixo, áreas de lazer, etc.;

- Adoção de equipamentos e ações de embelezamento e sinalização: jardinagem e paisagismo, mobiliário urbano, iluminação, etc.;

- Melhoria nos acessos e circulação: ciclovias, rotatórias, estacionamentos, etc.;

- Adoção de áreas verdes: criação de parques urbanos;

- Recuperação urbanística e do patrimônio: recuperação de fachadas e de casarios históricos, etc.

- Ordenamento e ações ambientais: estudos sobre a aplicação da Agenda Local 21, elaboração de planos de proteção ambiental, recuperação de espaços naturais, etc.;

- Diversificação e aumento da oferta turística: criação de pontos de informação turística, museus, trilhas, circuitos, mirantes, desenvolvimento do potencial de turismo de esportes, de atividades culturais e de turismo de eventos e negócios.

De fato, Secall (2012) destaca que os planos de excelência turística têm recebido atenção tanto da área administrativa como na esfera acadêmica. Diante disso, a autora identifica algumas convergências entre os pontos fortes, entendido como positivos e os pontos fracos, entendidos como negativos, elencados em estudos acadêmicos. Em relação aos pontos positivos e negativos, destacam-se:

\section{Quadro 03: Pontos positivos e negativos dos Planos de Excelência Turística}

\begin{tabular}{|c|c|}
\hline \multicolumn{2}{|c|}{ Planos de excelência turítica (SECALL, 2012) } \\
\hline Pontos Positivos & Pontos Negativos \\
\hline Impulso ao ordenamento e a gestão local; & $\begin{array}{l}\text { Baixo índice de participação do setor privado e da } \\
\text { sociedade como um todo; }\end{array}$ \\
\hline Fornecimento de conhecimento sobre os destinos; & $\begin{array}{l}\text { Maior parte das ações voltadas a melhoria dos } \\
\text { destinos urbanos; }\end{array}$ \\
\hline $\begin{array}{l}\text { Contribuição na coordenação entre a administração } \\
\text { pública e demais níveis administrativos; }\end{array}$ & Baixo financiamento; \\
\hline $\begin{array}{l}\text { Incentivo à participação do setor privado em } \\
\text { projetos criado pelo setor público; }\end{array}$ & Fraco planejamento estratégico; \\
\hline $\begin{array}{l}\text { Introdução da cultura da excelência e da qualidade } \\
\text { para o setor do turismo; }\end{array}$ & $\begin{array}{l}\text { Falta de mecanismos de acompanhamento e } \\
\text { avaliação dos planos; }\end{array}$ \\
\hline $\begin{array}{l}\text { Possibilidade de renovação do destino turístico e de } \\
\text { melhoria de sua imagem. }\end{array}$ & Dificuldade em dar continuidade às ações. \\
\hline
\end{tabular}

Fonte: Adaptado de Secall, 2012.

O conhecimento e gerenciamento desses aspectos pode vir a contribuir com a orientação e formulação de ações referentes à sazonalidade turística. Com o conhecimento antecipado de tais pontos negativos observados em estudos acadêmicos apontados por Secall (2012), é possível atentar-se para iniciar o estudo de um plano turístico de maneira que a implantação de alguma ação seja mais efetiva evitando a ocorrência de tais pontos.

Na Espanha, de acordo com Secall (2012), o último ano de concessão de Planos de Excelência Turística foi em 2006 e somaram um total de oitenta e quatro planos. Em termos espaciais, mais da metade estão localizados no litoral ou próximos. Sobre o tempo de duração, os investimentos financeiros poderiam variar entre três e quatro anos dependendo da avaliação recebida pelo projeto apresentado. Tal informação pode somar ao argumento da questão sazonal ser marcante nos destinos que se caracterizam essencialmente pelo segmento Sol e Praia e, ser a implantação de um plano, uma estratégia de minimizar tal fato.

A partir da experiência obtida com o funcionamento dos planos de excelência turística na Espanha, demonstra-se uma série de possíveis melhorias para a concepção de novas iniciativas de políticas para 
o turismo. Como exemplo, o Plano de Turismo Espanhol Horizonte 2020. Nesse plano há estratégias para a minimização da sazonalidade turística, de início por meio dos planos de dinamização do produto turístico (2006-2008) e, posteriormente com os planos de competitividade turística que, a partir de 2009, substituíram os planos de excelência (Plan de Turismo Español Horizonte 2020).

Segundo o Plano de Turismo Espanhol Horizonte 2020, muitos destinos turísticos espanhóis oferecem o turismo de Sol e Praia com marcante massificação o que vem contribuindo com a redução de sua procura nos últimos anos. Por essa razão, as ações de planejamento turístico espanholas concentram suas intenções no ordenamento da atividade turística, principalmente nos grandes fluxos do "turismo de massa" que são concentrados no litoral.

Para que o segmento turístico Sol e Praia espanhol possa atrair o mercado europeu como propõe o Plano de Turismo Espanhol Horizonte 2020, deve-se levar em conta as tendências sociodemográficas e posicionar-se em um ambiente competitivo onde se pode planejar uma maior segmentação da demanda.

Por isso, o documento Plano de Turismo Espanhol Horizonte 2020, aponta que a Espanha deve abordar, principalmente, os seguintes desafios para o produto Sol e Praia:

- Melhorar a qualidade paisagística e do meio ambiente, a massificação e a perda da identidade;

- Desenvolver uma oferta com altos níveis de serviços em todas as atividades turísticas envolvidas no produto Sol e Praia, configurando uma oferta combinada de serviços complementares;

- Incrementar o valor do produto Sol e Praia nos meses de inverno com a especialização e diferenciação dos destinos em tipos de turistas com perfil menos sazonal;

Ainda de acordo com o plano, ele constitui-se de propósitos dentre os quais destaca-se a intenção de incrementar a economia aumentando a rentabilidade dos agentes turísticos por meio da redução da sazonalidade. O documento fundamenta que essa orientação deve estar baseada em seis princípios: planejamento, equilíbrio e requalificação, diferenciação, especialização, simplificação e compromisso (Plan de Turismo Español Horizonte 2020).

Além dos princípios norteadores, o Plano de Turismo Horizonte 2020 desenvolve cinco eixos chaves estratégicos para atuação e desenvolvimento da atividade turística (Figura 03).

\section{Figura 03: Eixos de desenvolvimento da atividade turística;}

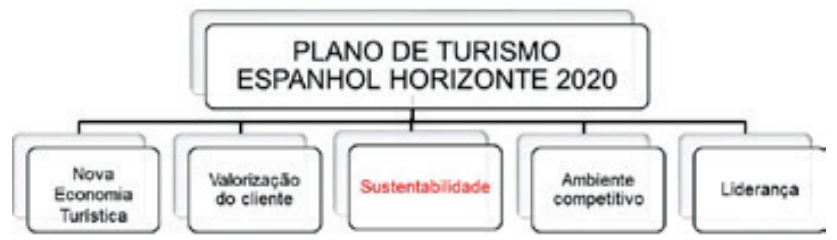

Fonte: Plano de Turismo Espanhol Horizonte 2020.

A preocupação com as questões referentes à sazonalidade turística encontra-se no eixo sobre sustentabilidade que, por sua vez, apresenta quatro estratégias: Turismo, meio ambiente e sociedade; Planejamento e gestão dos destinos turísticos; Requalificação dos destinos turísticos maduros / consolidados; (De)sazonalização e reequilíbrio socioterritorial. (Figura 04).

Figura 04: Eixo de desenvolvimento da atividade turística

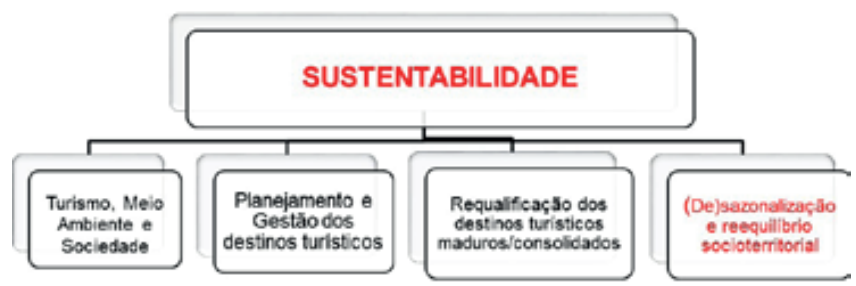

Fonte: Plano de Turismo Espanhol Horizonte 2020. 
A temática da sazonalidade pode ser percebida indiretamente nas estratégias 2 e 3 respectivamente, pois como já se evidenciou, o planejamento e a gestão são ferramentas necessárias para que o diagnóstico seja realizado e a partir disso, seja elaborado um plano adequado à realidade da localidade de que gere resultados efetivos e positivos.

A estratégia 3 que se refere à requalificação dos destinos turísticos maduros / consolidados, pode vir a afetar a questão da sazonalidade, isso porque uma requalificação adequada pode vir a gerar uma distribuição melhor no fluxo turístico anual para o destino, diminuindo os efeitos da sazonalidade.

A estratégia 4 já apresenta características diretas à temática da sazonalidade, onde a (De)sazonalização e Reequilíbrio Socioterritorial, significa revalorizar os recursos que fomentem o equilíbrio socioterritorial do turismo criando novos produtos capazes de funcionar durante todo o ano, minimizando a sazonalidade da demanda.

O plano se refere que a concentração territorial e a excessiva dependência de um único produto são alguns dos problemas mais relevantes que se depara o modelo turístico espanhol. Isso porque, o turismo espanhol esta concentrado principalmente no litoral e na temporada de verão.

Fica claro que é na estratégia 3, (De)sazonalização e Reequilíbrio Socioterritorial - que a sazonalidade de fato, é abordada. Onde o planejamento e a gestão irão possibilitar uma requalificação do destino turístico, através de diagnóstico, análise de características e consequências da sazonalidade na localidade.

O documento menciona ainda que, a capacidade do setor turístico em competir e gerar impactos socioeconômicos positivos está condicionada, em partes, ao crescimento competitivo fundamentado na sustentabilidade dos destinos que possuem uma maior capacidade de atrair novos segmentos de demanda (Plan de Turismo Español Horizonte 2020). No caso do turismo, a atração de novos segmentos de demanda deve referenciar-se na diferenciação dos elementos distintivos do território nos quais a oferta turística e sua respectiva promoção devem apoiar-se (Inostrosa e Cànoves, 2014).

Segundo Díez (2012), os destinos turísticos devem potencializar suas diferenças em relação a outros destinos para desenvolver estratégias de atração e turistas de turistas e investimentos que permitam o desenvolvimento turístico. Assim, as singularidades do território expressas nas diferenças entre os lugares correspondem às vantagens comparativas, que no caso do turismo estão constituídas pelos recursos endógenos do destino, como seus recursos naturais e culturais, sua localização geográfica em relação aos principais mercados turísticos, o clima, entre outros (Inostrosa \& Cànoves, 2014).

O Plano de Turismo Espanhol Horizonte 2020 aponta que a Espanha conta com exemplos bem sucedidos no que se refere à (de)sazonalização e ao reequilíbrio socioterritorial, mas atenta que os resultados obtidos devem ser constantemente atualizados, visto que o crescimento quantitativo dos destinos turísticos não garante nem a competitividade e nem maior rentabilidade.

A seguir, são apresentados três temas relevantes apontados pelo documento do Plano de Turismo Espanhol Horizonte 2020 como diretrizes essenciais à investigação e estudo referente à (de)sazonalização e ao reequilíbrio socioterritorial de um destino turístico:

\section{Figura 05: Diretrizes para a (de)sazonalização e ao reequilíbrio socioterritorial;}

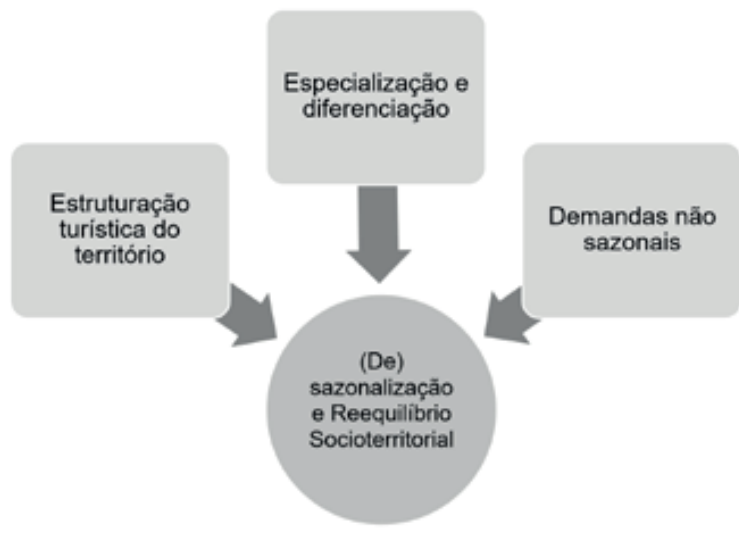

Fonte: elaboração própria, 2017. 
- Demandas não sazonais: As novas tendências da demanda geram novos segmentos que constituem oportunidades para os destinos turísticos espanhóis. A fragmentação do mercado consequência do surgimento de novos segmentos deve refletir em uma diversidade de produtos turísticos que tenham capacidade de atrair a demanda internacional e que complementem a oferta turística atual espanhola (Plan de Turismo Español Horizonte 2020, 2007);

- Especialização e diferenciação: os destinos turísticos devem impulsionar o desenvolvimento de novos produtos especializados ou diferenciados não apenas se basear na extensão dos produtos existentes para responder pontualmente a demandas complementares (Plan de Turismo Español Horizonte 2020, 2007);

- Estruturação turística do território: A Espanha dispõe de numerosos recursos e zonas com potencial para um maior aproveitamento turístico que podem responder a uma renovada estratégia produto-mercado de posicionamento. $\mathrm{O}$ crescimento competitivo e qualitativo conseguirá otimizar os resultados econômicos e sociais por capacidade de carga, diminuindo os impactos ambientais (Plan de Turismo Español Horizonte 2020, 2007);

O documento destaca que estas diretrizes oferecem um potencial de crescimento considerável, evitando que o modelo de desenvolvimento baseado na concentração da demanda, no consumo de produtos massificados e na obtenção de volume se reproduza em detrimento do destino turístico e de seu segmento prioritário.

Por fim, em relação à (de)sazonalização e ao reequilíbrio socioterritorial, de acordo com o Plano de Turismo Espanhol Horizonte 2020, em resposta aos estudos e teorias, as ações devem ter como objetivo o alcance ao desenvolvimento efetivo de uma nova categoria de produtos turísticos que impulsione o desenvolvimento qualitativo dos destinos respondendo às exigências de diferenciação e especialização exigidas pelo mercado, evidenciando o planejamento estratégico integrado.

\section{Considerações Finais}

O turismo, elemento importante de incentivo e estímulo ao desenvolvimento local e regional, para gerar um desenvolvimento equilibrado precisa contar com um planejamento integrado e participativo. O planejamento, acima de tudo, é capaz de provocar mudanças estruturais, institucionais ou comportamentais desejadas por um grupo social ou por alguma instituição, de forma que o resultado final represente uma oportunidade de melhoria para a coletividade, em termos de benefícios e impactos positivos, o que ocorrerá mais rápido e facilmente dependendo da participação e integração dos atores envolvidos no processo.

O planejamento deve ser considerado como um processo contínuo e permanente, dentro de um espaço de tempo definido, utilizando instrumentos apropriados para a tomada antecipada de decisões, através da simulação de uma situação futura desejada (Hall, 2001), onde a função básica do planejamento é otimizar os recursos urbanos, naturais, artificiais e culturais existentes de acordo com as premissas da sustentabilidade, e incrementar a demanda turística de forma racional nos espaços disponíveis para o exercício da prática de atividades turísticas.

Destaca-se que a sazonalidade é uma temática importante a ser trabalhada no planejamento turístico dos destinos turísticos, onde a falta de instrumentos de planejamento representa a possibilidade de uma ocorrência da atividade turística desordenada e com pouco entendimento entre as dinâmicas turísticas representando a desregulamentação da atividade.

Visto que a sazonalidade é um problema de larga duração que afeta muitas atividades e muitos destinos turísticos, torna-se uma questão relevante para os gestores considerarem essa temática em suas ações (Bonilla \& Bonilla, 2006).

No caso espanhol, mesmo com um crescimento do fluxo turístico durante o restante do ano, a concentração do fluxo turístico para a Espanha continua alta no verão. Isso reflete na elevada sazonalidade que gera a saturação dos destinos na alta temporada afetando os níveis de satisfação da demanda (Plan de Turismo Español Horizonte 2020).

Os Planos de Excelência Turística constituíram uma das mais importantes iniciativas da política turística espanhola Secall (2012), visto que levantou diversas possibilidades para melhorar a qualidade dos destinos turísticos, dentre elas: o impulso ao ordenamento e a gestão local, o fortalecimento do conhecimento sobre os destinos turísticos, o desenvolvimento de pesquisas que identificassem o perfil do 
turista, a contribuição na coordenação entre a administração pública e demais níveis administrativos; o incentivo à participação do setor privado em projetos criados pelo setor público e a introdução da cultura da excelência e da qualidade para o setor do turismo.

Os planos de excelência turística espanhóis apresentam-se como um reflexo de uma nova cultura turística, baseada no tratamento integral do destino turístico, analisando todas as informações disponíveis desde dados do destino até pesquisas do perfil do turista, incluindo a participação de diversos agentes econômicos e sociais com a justificativa de que uma das condições do plano seja introduzir ações que objetivem melhorar a totalidade do destino (Bosque, 2004; Secall, 2012).

O plano Espanhol Horizonte 2020 aponta como desafios que devem ser adotados para o produto Sol e Praia, a perspectiva de uma oferta combinada de serviços complementares, com altos níveis de serviços em todas as atividades turísticas envolvidas (Plan de Turismo Español Horizonte 2020).

Além disso, não apenas diversificar a oferta é o suficiente para melhor atrair e distribuir a demanda. Outro argumento aparece no plano espanhol citado ao afirmar como desafio para o produto Sol e Praia incrementar o valor do produto nos meses de inverno com a especialização e diferenciação dos destinos em tipos de turistas com perfil menos sazonal. Isso significa que é necessário, além de diversificar, especializar o produto para que ele se diferencie dos demais concorrentes.

A ideia de diferenciação e complementariedade deve ser potencializada para a atração de novos segmentos de demanda referenciando-se nos elementos distintivos do território nos quais a oferta turística e sua respectiva promoção devem apoiar-se para desenvolver estratégias de atração e turistas de turistas e investimentos que permitam o desenvolvimento turístico (Díez, 2012; Inostrosa \& Cànoves, 2014).

Tal entendimento é um exercício para uma projeção de complementaridade e diferenciação com o objetivo de equilibrar melhor a demanda do produto turístico Sol e Praia.

Em relação à especialização e diferenciação, relacionam-se ideias voltadas ao fortalecimento do destino turístico em suas especificidades e à qualificação do profissional dos atores envolvidos na atividade turística. Sobre as especificidades do destino, elas podem gerar atratividade por novas demandas, por diferenciar-se de outros destinos. Já a qualificação profissional, envolve desde a concepção do destino à sua divulgação, passando pelo contato direto com os turistas no momento de sua permanência no destino.

O turismo, por ser uma combinação complexa de serviços, é uma atividade de utilização intensa de capital humano [e o] ensino e a consequentemente formação de mão-de-obra especializada poderão responder aos desafios que o setor enfrenta (Ansarah, 2002). A qualificação profissional, ao inserir e envolver a comunidade torna-se uma chave para a aceitação e o desenvolvimento da atividade turística.

Além disso, é importante a manutenção e disponibilização de um banco de dados integrado e atualizado do inventário da oferta, pesquisa e estatística dos serviços turísticos, possibilitando o gerenciamento das informações turísticas do destino. Essa ação deve ser o ponto de partida para se pensar na diferenciação e especialização do destino, pois só o conhecendo é possível gerar ações e direcioná-las.

Diante da importância e pertinência do assunto abordado é possível afirmar que a pesquisa contribuiu para o reconhecimento da importância da temática da sazonalidade no desenvolvimento do planejamento turístico e de seus instrumentos.

Da experiência obtida pelo conhecimento dos planos turísticos espanhóis referenciados é possível desmembrar uma séria de novos planos e iniciativas de política turística, assim como definir novos objetivos, fomentar a cooperação entre iniciativas públicas e privadas e entre localidades distintas, buscar novas formas de trabalhar a sustentabilidade do destino e de ajustar às necessidades específicas locais.

Seja em qualquer esfera de atuação, compreender a sazonalidade e suas especificidades locais, além das necessidades e expectativas da população local e do turista, é uma das maneiras de gerenciar o destino turístico e ter conhecimento sobre as ferramentas e possíveis ações de oferta para trazer o equilíbrio na demanda ou, direcioná-lo para o período desejado do ano. Além de obter conhecimentos sobre o reflexo da ocupação ou da falta dela nos distintos meses do ano e poder gerenciar ações locais de ordem social, ambiental, política e estrutural. Com isso, foi possível identificar a relevância do planejamento turístico para um destino, considerando a suas especificidades de oferta e demanda para ações direcionadas e fundamentadas no combate à sazonalidade, melhorando consequentemente a qualidade dos serviços especialmente, durante a alta temporada.

Diante da crescente importância da atividade turística e seu consequente papel para economia e para a sociedade, observado que o Brasil ainda é carente em estudos que tenham como foco minimizar / atenuar a sazonalidade turística de modo a reverter as ações em benefícios para as localidades, espera-se com esse estudo contribuir com a oportunidade de apresentar e desenvolver ações tendo como base planos de turismo de destino turístico de referência mundial que abordam com especificidade a temática da sazonalidade, como é o caso da Espanha. 
Uma das possibilidades seria uma parceria entre as organizações públicas e as privadas de modo que se realize levantamento de dados de oferta e demanda e identifique possibilidade de ações conjuntas. A complementaridade de ações entre destinos turísticos de segmentos distintos pode ser uma estratégia para minimizar / atenuar a sazonalidade, visando desenvolver o de mais oportuno para cada período. Essa oportunidade vem a contribuir na medida em que o estudo desenvolvido possa ser replicado a demais destinos turísticos brasileiros.

\section{Bibliografia}

Allcock, J. B.

1989. Tourism Marketing and Management Handbook. In S. Witt., e L. Moutinho (Eds.) Hertfordshire:

Prentice - Hall Internacional, 92-104.

Almeida, A. L., e Kastenholz, E.

2008. A sazonalidade no turismo e a estratégia de diversificação da procura: O Caso do Norte de Portugal.

$2^{\circ}$ Encontro Luso-Brasileiro de Estratégia. Disponivel em http://www.atsie.com/Portals/4/artigos/A\%20 sazonalidade\%20no\%20Turismo.pdf. Acesso 25 de Março de 2017.

Ansarah, M. G. R.

2002. Formação e Capacitação do Profissional em Turismo e Hotelaria: reflexões e cadastro das instituições educacionais do Brasil. São Paulo: Aleph.

Baron, R.

1975. "Seasonality in Tourism: a guide to analysis of seasonality". Economist Intelligence United, Technical Paper 2.

Baum, T., e Lundtorp, S.

2001. Seasonality in Tourism. Oxford: Pergamon.

Bonilla, J.M.L.; Bonilla, L.M.L.

2006. "La concentración estacional en las regiones españolas desde una perspectiva de la oferta turística".

Revista de Estudios Regionales, 77(1): 77-104.

Bosque, R. L.

2004. "La política de calidad em lós destinos turísticos em Espana: el ejemplo del plan de excelência turística em el Valle de Tena". Cuadernos Geográficos, 34 (1): 179-195.

Butler, R.

1994. "Seasonality in Tourism: issues and problems (pp. 332-339)". In: Seaton et al. (Eds.). Tourism - The

State os the art. (pp. 332-339). Chichester: Wiley.

Butler, R.

2001 "Seasonality in Tourism: issues and implications". In Baum, e S. Lundtorp (Eds), Seasonality in tourism. Oxford: Pergamont.

Cisneros-Martínez, J. D., e Fernández-Morales, A.

2013. Cultural tourism as tourist segment for reducing seasonality in a coastal area: the case study of Andalusia. Current Issues in Tourism.

Correa, A.

1994. A População e mercados turísticos no Algarve - Estratégias de negócio e dessazonalização.

(Dissertação de Mestrado em Economia). ISEG, Universidade Técnica de Lisboa.

Coshall, J., e Charlesworth, R. e Page.

2015. "Seasonality of Overseas Tourism Demand in Scotland: A Regional Analysis". Regional Studies, 49(10):1603-1620.

Costa, C.

2001. "An Emerging Tourism Planning Paradigm? A comparative analysis between town and tourism planning". Internacional Journal of Tourism Research $3: 425$-441.

Dencker, A. F.

1998. Pesquisa em turismo: planejamento, métodos e técnicas. São Paulo: Futura.

Departamento Geral De Turismo De Madrid. Dirección General De Turismo.

1998. Planes de excelencia y dinamización turística. Madrid: Secretaría de Estado de Comercio, turismo y PYME. Dirección General de Turismo. 
Díez, D.

2012. "La competitividad turística en espacios interiores: una propuesta metodológica para la determinación de competidores potenciales". Cuadernos de Turismo, 30(1): 109-125.

Duro, J. e. Farré, F.X

2015. "Estacionalidad turística en las provincias españolas: medición y análisis". Cuadernos de Turismo, 36(1): 157-174.

Koeing N. e Bischoff E. E.

2003. "Seasonality of tourism in Wales: a comparative analysis". Tourism Economics, 9(3): 229-254.

Ferrari, J.

2004. "Limites E Potencialidades Do Planejamento Urbano. Uma Discussão Sobre Os Pilares E Aspectos Recentes Da Organização Espacial Das Cidades Brasileiras”. Estudos Geográficos, 2(1): 15-28.

Gil, A. C.

2009. Como elaborar projetos de pesquisa (4 ed.). São Paulo: Atlas.

Gobierno De España. Ministerio de Industria, Turismo y Comercio.

2015. Plan de Turismo Español 2020.Disponível em http://www.tourspain.es/eses/VDE/Documentos\%20

Vision\%20Destino\%20Espaa/Pla n_Turismo_Espa\%C3\%B1ol_Horizonte_2020.pdf. Acesso em 26 de Nov de 201.

Godoy, A. S.

1995. "Introdução à pesquisa qualitativa e SUS possibilidades". RAE - Revista de Administração de Empresa, 35(2): 57-63.

Hall, C. M.

2001. Planejamento turístico: políticas, processos e relacionamentos. São Paulo: Contexto.

Inostrosa, G. e.

2014. "Turismo sostenible y proyectos hidroeléctricos: contradicciones en la patagonia chilena". Cuadernos de Turismo, 34(1):115-138.

Ivars, J. A.

2003. Planificación turística de los espacios regionales en España. Madrid: Editorial Síntesis.

Jang, S.

2004."Mitigating tourism seasonality: a quantitative approach". Annals of Tourism Research, 31(4): 819-836.

Karski, A.

1990. "Urban Tourism - a key to urban regeneration". The Planner, 76(13): 15-17.

Koenig-Lewis, N., e Bischoff, E.

2005. "Seasonality research: the state of the art". International Journal of Tourism Research, 7: 201-219.

Koži , I.

2013. "Kolika je sezonalnost turizma u Hrvatskoj”. Ekonomski Vjesnik, 470-480.

Law, R.

2006. "The perceived impact of risks on travel decisions". International Journal of Tourism Research, 8(1):289-300.

Lee, C., Bergin - Seers, S., Galloway, G. B., e McMurray.

2008. Sesonaitiy in Tourism Indurstry (Impacts and Strategies). Australia: CRC for Sustainable Tourism: Gold Coast.

Leite, F. L.

2016. "Parques Urbanos de Curitiba (PR): Espacialidade, Planejamento, e Turismo". Anais do XIV Encontro Nacional de Turismo de Base Local - ENTBL - Resumos Revista Brasileira de Ecoturismo, 9(5):22. Michel, M. H.

2005. Metodologia e pesquisa científica em ciências sociais: um guia prático para acompanhamento da disciplina e elaboração de trabalhos monográficos. São Paulo: Atlas.

Molina, S.

1997. Turismo: metodologia para su planificación. México : Trilhas.

Munhoz, D.

1989. Economia aplicada: técnicas de pesquisa e análise econômica. Brasília: UNB.

Rebollo, J. F. V; Castiñeira, C. J. B.

2010. "Renovación y reestructuración de los destinos turísticos consolidados del litoral: las prácticas recreativas en la evolución del espacio turístico". Boletín de la Asociación de Geógrafos Españoles, 53: 329-353. 
Richardson, R.

1999. Pesquisa Social (3 ed.).São Paulo: Atlas.

Roblez, C. e.

2009. "La apuesta por la calidad como elemento diferenciador en los destinos turísticos: planes renovados".

Cuadernos de Turismo, 23: 89-110.

Ruschmann, D.

2004. Turismo e Planejamento Sustentável: a proteção do meio ambiente. Campinas: Papirus.

Secall, L. B.

2012. Planes de excelencia turística en españa (1992-2006). Una apuesta por la revitalización de los destinos. Revisión de su implantación e impactos. Scripta Nova, 16: 411.

Secareanu, C., e Firoiu, D.

2011. "Statistical Methods Used in the Anaylsis and Foercast of the Tourism Activity Affected by Sesonaity". Romanina Economic and Business Review, 6(4): 150-157.

Scheuer (2011:291

Soares, J. C.

2012. La evolución de los destinos turísticos litorales consolidados. Un análisis comparado de Balneario Camboriú (Brasil) y Benidorm (España). (Tese de Doutorado) Instituto Universitario de Investigaciones Turísticas, Universidad de Alican.

Trajkov, A., Biljan, J., e Andreeski, C.

2016. "Overview and Characteristics of Tourism Seasonality in Ohrid". Economic Themes, 54(4): 485-498. Turespaña -Instituto De Turismo De España.

2016.TURESPAÑA, Disponível em http://www.spain.info/pt_BR/reportajes-portales/Brasil/about_us.html. Acesso 25 de Março de 2017.

Urry, J.

1995. The Tourist Gaze: Leisure and Travel in contemporary Societies. Londres: Sage Publications.

WTTC - World Travel and Tourism Council.

2017. Economic Impact Research. Disponível em http://www.wttc.org. Acesso em 25 de Março de 2017. WEF - World Economic Forum.

2015. The Travel \& Tourism Competitiveness Report 2015. Acesso em Março de 25 de 2017, disponível em http://www3.weforum.org/docs/TT15/WEF_Global_Travel\&Tourism_Report_2015.pdf . 